\title{
A NEW SPECIES OF LIGYROCORIS STAL WITH A KEY TO THE NORTHEASTERN SPECIES (HEMIPTERA : LYGAEIDAE)
}

\author{
By Merrill H. SweEt ${ }^{1}$ \\ Department of Zoology and Entomology, University' of Connecticut
}

In the course of current work upon the biology and ecology of the Rhyparochrominae of New England, a new species of Ligyrocoris was discovered. The species runs in Barber's (I92I) key to the couplet separating diffusus (Uhler) from sylvestris (L.), but is distinct from either species. While the new species is closely related to these species, it is also quite close to L. depictus which is separated out in a different part of Barber's key.

These four closely related species are sympatric in New England, although they are markedly different in their overall distribution. The habitat preferences and life cycles of the species are quite different (Sweet, unpublished). The habitat of the new species described below is most unusual for the genus. The greater part of the type series was collected along the margin of a small pond where sedge clumps were standing in the water among occasional exposed rocks rather than in relatively dry fields or slope habitats where the other species occur. The species feeds upon the seeds of the sedge, Carex stricta Lam., and its life cycle is apparently adapted to that of the sedge, which fruits in late May and June. The insect becomes adult in mid-June and lays eggs until mid-July. The eggs remain in diapause over the summer and winter and hatch in May.

\section{Ligyrocoris caricis n. sp.}

Male: general body coloration black; posterior lobe of pronotum fuscous, becoming pale on humeral angles; connexivum and trichobothrial spots fuscous; acetabula, posterior margin of metapleuron and apex of scutellum pale; hemelytra patterned pale and brown; lateral margin of corium pale except for fuscous apex; at least apical half of clavus and corium brown, becoming dark at inner angle of corium; post median brown area (fascia) extending toward but not reaching lateral margin of corium; pale spots behind inner corial angles faint or absent; membrane infuscated with base, apex and veins pale; legs mostly flavescent; coxae, terminal tarsal segment, and ring on base of hind tibia fuscous; fore femora and apical portion of

\footnotetext{
${ }^{1}$ Written during tenure of a National Science Foundation Fellowship. Manuscript received by the editor June 15, 1962.
} 
hind femora light brown ; antennal segments one, two, and basal twothirds of three flavescent, remainder fuscous; apex of tylus and entire labium brown, except fuscous apex of fourth labial segment; entire body clothed with fine, adpressed, shining hairs, densely so on head and abdomen, sparsely on hemelytra and thorax, pronotum nearly nude; long erect setae present on hemelytra and thorax, pronotum nearly nude; long erect setae present on entire dorsum, but with very few (ca. IO) on pronotum; head trichobothria one-third longer than other head setae; a few finer secondary head setae present behind eyes and ocelli and along meson; appendages with short fine semierect pale hairs. Head very finely punctate except on lorum and apex of tylus; hemelytra and entire thorax very finely granulose, dull; anterior lobe of pronotum, scutellum, thoracic pleura and sterna with fine sparse punctures; posterior thoracic lobe with scattered but definite punctures; hemelytra with three rows of punctures on clavus, two on corium along claval suture, and one lateral to radial vein, the rows becoming suffused posteriorly. Body small and slender for genus; head narrowed behind eyes, porrect; antennal segment one barely exceeding tylus; ocelli small, remote (.I $4 \mathrm{~mm}$.) from eyes; eyes oval, not especially produced; postocular distance smaller than anteocular distance to apex of antenniferous tubercules; length of head $.75 \mathrm{~mm}$., width across eyes $.96 \mathrm{~mm}$., interocular distance $.59 \mathrm{~mm}$.; pronotal lobes distinctly but not incisively separated by transverse constriction (fig. 3) ; pronotal collar weakly differentiated from pronotum; anterior lobe rounded laterally and dorsally, and high and convex in profile; hind lobe with slightly raised and obtusely rounded lateral margins, hind margin slightly concave; pronotum length $.96 \mathrm{~mm}$., anterior lobe $.63 \mathrm{~mm}$., width across posterior lobe I.I I mm., across anterior lobe $.90 \mathrm{~mm}$; scutellum with weak posterior carina crossed by fine transverse grooves; length $.77 \mathrm{~mm}$., width $.55 \mathrm{~mm}$.; brachyterous, hemelytra narrow, membrane reaching tergum 7; lateral margin slightly sinuate at level of tip of scutellum; length of commissure $.37 \mathrm{~mm}$.; distance apex of clavus-apex corium .78 mm., apex coriumapex abdomen $.74 \mathrm{~mm}$.; hind wing three-fourths length of hemelytra; scent gland peritreme slightly raised, rounded, the coarsely granulose evaporatorium covering lower two fifths of metapleuron; parameres slender, pointed; posterior portion of pygophore slightly excavate; aedeagus similar to L. sylvestris (L.) (Ashlock I957); abdomen with stridulatrum (stigose vittae) gently arching from sternum 2 to posterior margin of 4 ; plectrum on hind femora consisting of a field of 20 small tubercules; fore femora moderately incrassate, armed beneath with an inner distal row of spines consisting of two large 
spines each followed distad by three small spines, the outer row with two weak apical spines; length fore femora $1.18 \mathrm{~mm}$.; length of hind tarsal segments I $.63 \mathrm{~mm}$., II and III .3I $\mathrm{mm}$.; meso- and meta-tibia with three inner rows of spines; labium not exceeding mesocoxae, length of segments I .56 mm., II .59 mm., III .48 mm., IV .37 mm.;

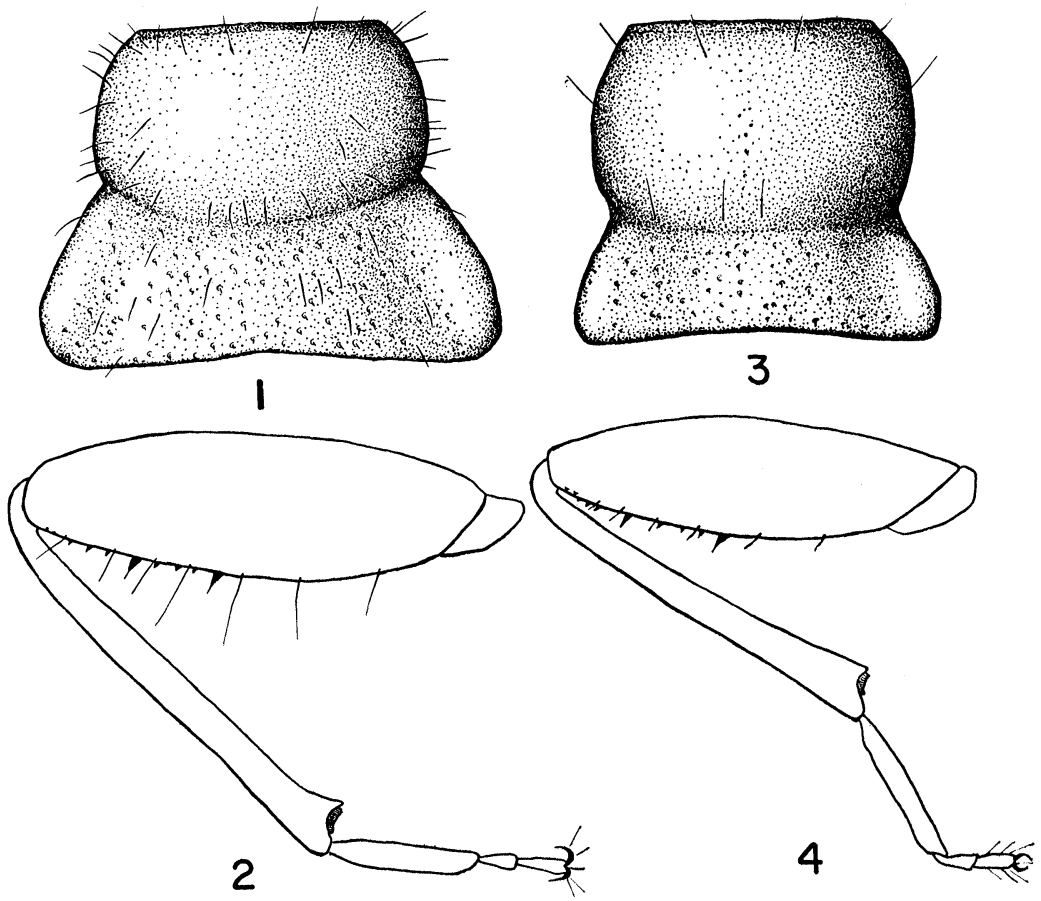

Figs. 1-4. Ligyrocoris. 1, pronotum of L. diffusus (Uhler) ; 2, fore femora of $L$. diffusus (Uhler); 3 , pronotum of $L$. caricis $n$. sp.; 4, fore femora of L. caricis n. sp.

antennae relatively long, length of segments I .56 mm., II .94 mm., III $.85 \mathrm{~mm}$., IV I.07 mm. Total length $4.8 \mathrm{I} \mathrm{mm}$.

Holotype: Male. Storrs, Connecticut (Pink Ravine) June 27, 1960 (M. Sweet). In United States National Museum. Type No. 66324.

Paratypes: Same locality as holotype. 9 males, 5 females, 3 nymphs. June 25, 27, July I I, I960; June 27, 28, I96I. 2 females, 3 nymphs. Mt. Desert Island, Maine (Great Heath) July 8, I955 (F. B. Shaw). In United States National Museum, Museum Comparative Zoology (Harvard), California Academy of Sciences, British Mu- 
seum (Nat. Hist.), University of Connecticut, J. A. Slater, P. D. Ashlock, and author's collections.

From the other species of Ligyrocoris sensu stricto, L. caricis is readily distinguished by its relatively small size and narrow form. Like diffusus, caricis has an incomplete fuscous fascia on the hemelytra, smaller size, and the hind basal metatarsal segment only twice the length of the distal two combined. However, caricis appears to be more closely related to the larger species depictus and sylvestris for it shares with them a relatively narrow pronotum with very few erect setae, fore femora with short setae or none, a labium which only attains the mesocoxae, relatively long antennae, a similar pattern of spines on the aedeagal conjunctiva, and a brachypterous condition. L. slossoni Barb. differs in having a labium which attains the third abdominal segment and a complete fascia on the hemelytra.

It should be noted here that the fascia which Barber (I92I) used as a major character to separate species is quite variable, and specimens of depictus will go to both sides of Barber's key on this character. Actually depictus is very closely related to $L$. sylvestris rather than to the very different $L$. litigiosus Barb. and other species which lack the fascia.

As all the species mentioned above are closely related, it is fortunate that the species concepts could be verified by mating experiments. In all four species, caricis, diffusus, sylvestris, and depictus, the males display a courtship "dance." When a female was approached by a male of a different species, she became extremely excited, and actively avoided the strange male so that cross-mating does not occur. This behavior is entirely different from the normal "reluctant response" of a female to a male of the same species. These behavior patterns will be discussed in detail in a later contribution.

Key to the Species of Ligyrocoris of the Northeastern United States I. Pronotum with many (ca. 25 or more) erect setae (Fig. I) ; fore femora with outer row of setae present and longer than basal width of fore tibiae (Fig. 2); labium reaching between hind coaxe; labial segments II and III subequal $(.70: .67 \mathrm{~mm}$.) ; nearly always macropterous with membrane of hemelytra reaching beyond tergum 7 diffusus (Uhler) Pronotum with few (ca. Io) erect setae (Fig. 3); fore femora without an outer row of short setae, if present (Fig. 4), length always less than basal width of fore tibiae; labium not reaching between metacoxae, usually just attaining mesocoxae; labial segment III shorter than II, often subequal to I (at most, II .8I $\mathrm{mm}$., III .70 mm.) ; always brachypterous, membrane of hemelytra rarely reaching beyond tergum 7 
2. Basal hind tarsal segment only twice combined length of distal segments $(.67: .33 \mathrm{~mm}$.) ; size small (length, 4.77 to $5.18 \mathrm{~mm}$.) ; post median transverse fascia on corium not attaining lateral margin of corium; metapleura never inflated, invisible from above caricis n. sp. Basal hind tarsal segment nearly three times combined length of distal segments $(.92: .34 \mathrm{~mm}$.) ; size larger ( 5.16 to $7.47 \mathrm{~mm}$.) ; post-median transverse fascia either present or nearly absent, but if evidently present then attaining corial margin; metapleura in male frequently inflated and visible from above

3. Post-median transverse fascia fuscous and broadly attaining lateral margin of corium; labial segment III longer than I (.70:.63 mm.) ; pale spot at mesal angle of corium faint or absent; basal and apical pale spots on membrane never confluent; fore femora usually fuscous ........................................ sylvestris (Linnaeus) Post-median transverse fascia weak, ferrugineous, often absent; labial segment III shorter than I $(.57: .67 \mathrm{~mm}$.) ; pale spots at mesal angle of corium distinct; basal and apical pale spots on membrane usually confluent, fore femora usually light yellow brown depictus Barber

The above key does not include L. obscurus, L. litigiosus, L. abdominalis, L. multispinus, and L. slossoni which have a more southern distribution and are adequately separated in Barber's original keys, or Torre-Bueno's ( 1946) adaptation of it. As discussed by Ashlock (1957) the aedeagal spines will prove very useful in establishing group relationships in this genus, but they are of little value in distinguishing the species included in the above key.

\section{AcKnowledgements}

I wish to express my grateful thanks to Dr. R. C. Froeschner (United States National Museum) for a loan of specimens and to Dr. James A. Slater (University of Connecticut) for allowing me to use his extensive collection and for critically reading the manuscript.

Ashlock, P. D.

\section{References Cited}

1957. An investigation of the taxonomic value of the phallus in the Lygaeidae (Hemiptera-Heteroptera). Ann. Ent. Soc. Amer. 50: $407-426$.

BARBER, H. G.

1921. Revision of the genus Ligyrocoris Stal (Hemiptera, Lygaeidae). Jour. N. Y. Ent. Soc. 29: 100-114.

Torre-Bueno, J. R.

1946. A synopsis of the Hemiptera-Heteroptera of America north of Mexico. Part III. Family XI. Lygaeidae. Ent. Amer. 26(1-3): 1-141. 

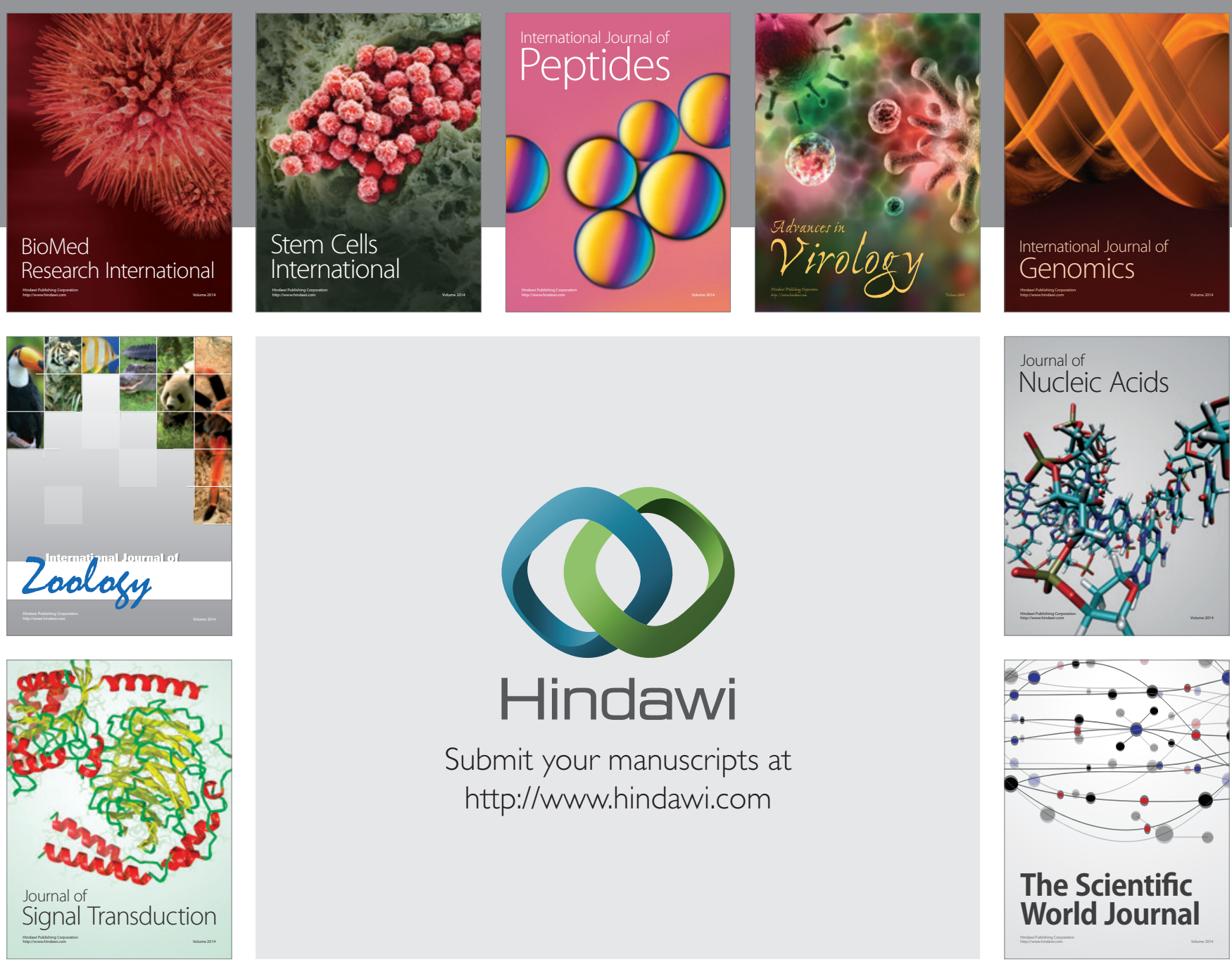

Submit your manuscripts at

http://www.hindawi.com
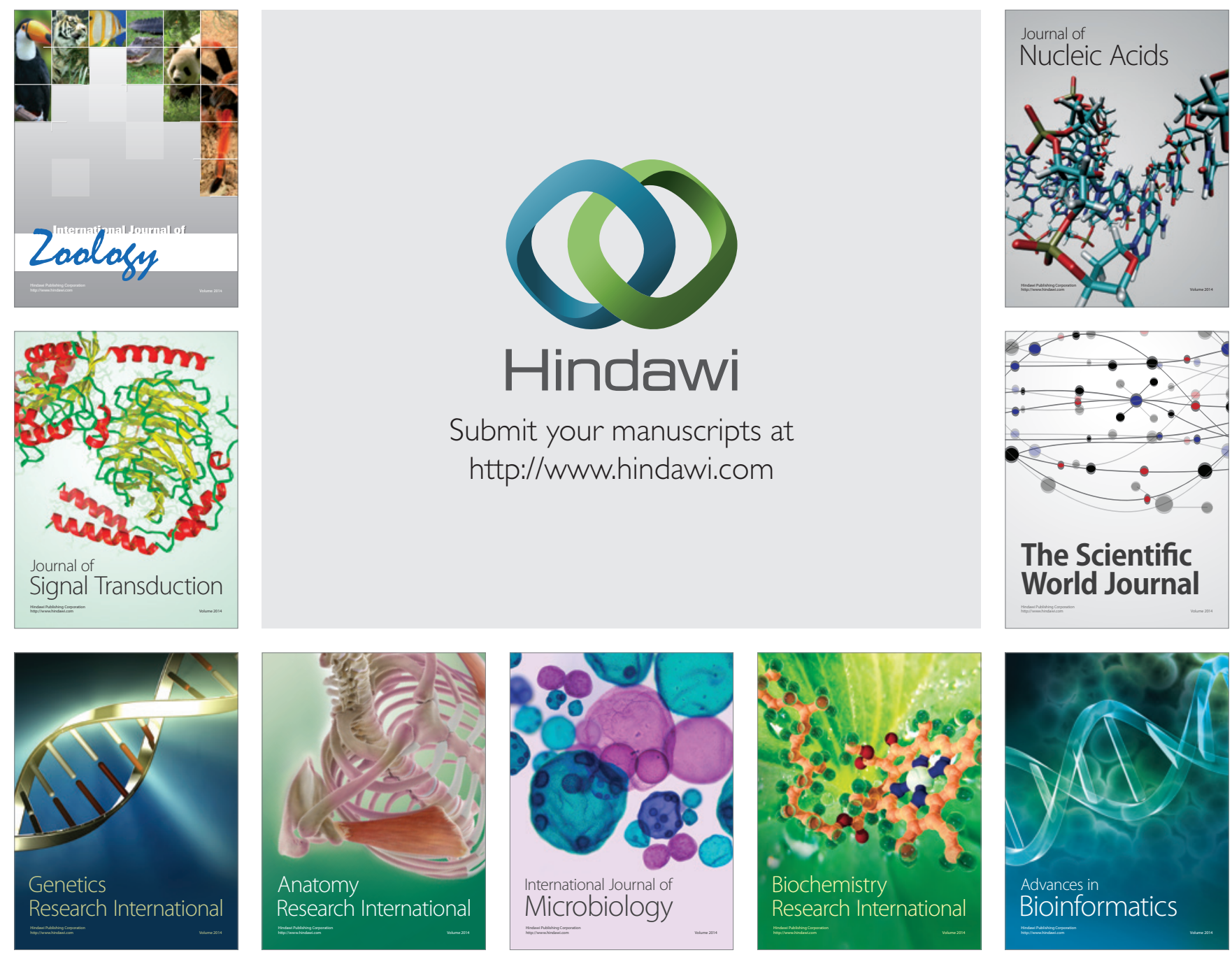

The Scientific World Journal
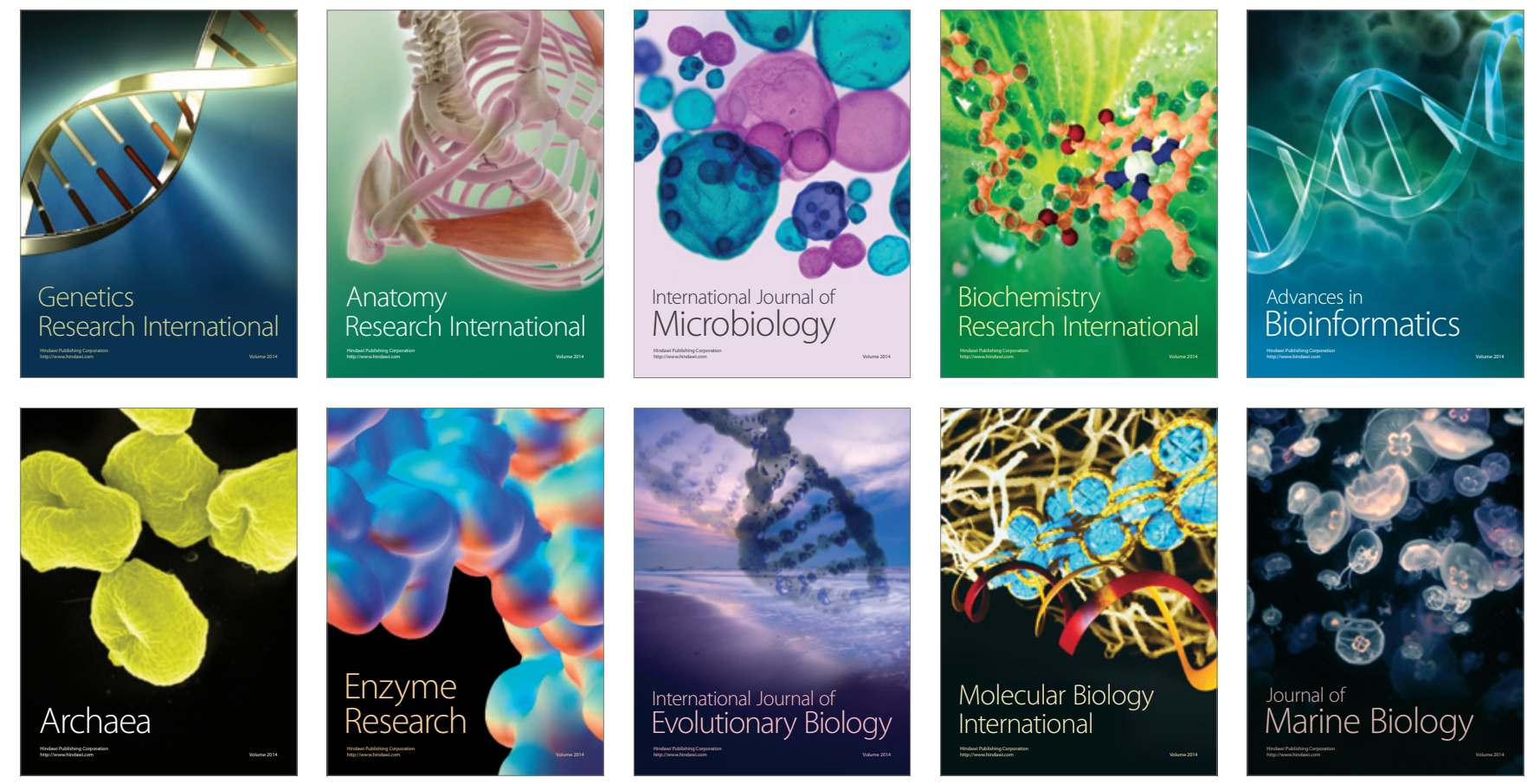